\title{
Rabaska
}

Revue d'ethnologie de l'Amérique française

Burgess, JoAnne et PAUl-ANDré LinteAu (dir.). Histoire et patrimoine. Pistes de recherches et de mise en valeur. Québec, Presses de l'Université Laval, « Chaire Fernand-Dumont sur la culture, INRS », 2019, 236 p. ISBN 978-2-7637-4329-5

\section{Cylvie Claveau}

Volume 18, 2020

URI : https://id.erudit.org/iderudit/1072929ar

DOI : https://doi.org/10.7202/1072929ar

Aller au sommaire du numéro

Éditeur(s)

Société québécoise d'ethnologie

ISSN

1703-7433 (imprimé)

1916-7350 (numérique)

Découvrir la revue

Citer ce compte rendu

Claveau, C. (2020). Compte rendu de [BURGESS, JOANNE et PAUL-ANDRÉ LINTEAU (dir.). Histoire et patrimoine. Pistes de recherches et de mise en valeur. Québec, Presses de l'Université Laval, "Chaire Fernand-Dumont sur la culture, INRS », 2019, 236 p. ISBN 978-2-7637-4329-5]. Rabaska, 18, 329-331.

https://doi.org/10.7202/1072929ar d'utilisation que vous pouvez consulter en ligne. 
les sangs, entre-eux ; et qui, tout en passant par le moule canadien-français, conserverait le souvenir de son origine, en s'appelant métisse. » Son «rêve » a résonné aussi fort dans le cœur et l'esprit des Métis que l'appel de Martin Luther King chez les Afro-Américains. Sa mémoire a cimenté leur culture et revivifié la reconnaissance de leurs droits, tel que le rappelle Marie-Joseph Riel en 1985, citée par les auteurs : «Mais nous qui portons le nom de Riel dans la réalité et dans notre cœur, nous sang-mêlé, nous métis. [sic] Allonsnous rester dans le fond du trou pendant que des choses se passent autour de nous ? » Pour le jeune Noël, que les Blancs appellent « le grand Métis » et les Métis, « le grand Bois-Brûlé », à cause de sa taille, « le héros incontesté de notre famille est Louis Riel. Il ne se passe pas une semaine sans que j'entende parler de ce grand homme. Il fait partie de nos vies. Son histoire est ancienne, mais encore vivante dans l'esprit des Métis. [...] J'aime les récits qui parlent de cet homme hors du commun. Je les connais tous par cœur. » Les Métis de l'Outaouais témoignent encore aujourd'hui, en se reconnaissant dans le rêve de Riel, qu'ils sont des passeurs d'une culture authentique, vivante et unique.

Voilà la grande et forte leçon de ces deux livres qui parlent en faveur des Métis de l'Outaouais, à l'unisson, d'une seule voix. Bouclant la boucle, ces deux livres ont remporté chacun un prix prestigieux pour leur qualité exceptionnelle, le Prix 1997 de littérature jeunesse (texte) du Gouverneur général dans le cas de Michel Noël, et le Prix du Canada en sciences humaines et sociales 2020 pour le trio Bouchard-Mallette-Marcotte.

RENÉ BouCHARD

Société québécoise d'ethnologie

Burgess, Joanne et Paul-André Linteau (dir.). Histoire et patrimoine. Pistes de recherches et de mise en valeur. Québec, Presses de l'Université Laval, " Chaire Fernand-Dumont sur la culture, INRS », 2019, 236 p. ISBN 978-2-7637-4329-5.

Cet ouvrage présente les résultats de recherches menées en partenariat ou dans le cadre du volet histoire appliquée de la maîtrise en histoire de l'UQÀM entre 2004 et 2014 par le Laboratoire d'histoire et de patrimoine de Montréal (LHPM). Prenant la suite du Groupe de recherche sur la société montréalaise au XIX ${ }^{\mathrm{e}}$ siècle (1972-1987), devenu le Groupe de recherche sur l'histoire de Montréal (1987-2006), le laboratoire oriente ses recherches vers la mise en valeur des patrimoines urbain, archéologique, muséologique, immobilier, archivistique et immatériel depuis 2006. Autour du thème « Villes : espaces, cultures et sociétés », quatre pôles structurent la recherche : Montréal, histoire 
et patrimoine, le recours au numérique, la mise sur pied d'un système de cartographie de l'histoire de Montréal (Schema) et l'histoire au cœur de la Cité. En 2016, un colloque tenu dans le cadre de l'AcFAs sous le thème « De l'histoire au patrimoine : état des lieux et perspectives » est à l'origine de cette publication.

La première partie de l'ouvrage porte sur les usages de l'archéologie en histoire. Pierre Desrosiers et Sophie Limoges considèrent l'appropriation du patrimoine archéologique au Québec et sa médiation dans la constitution des collections des musées, leur conservation, leur mise en exposition et leur numérisation en 3D.

Trois autres études de cas dans la quatrième partie illustrent ce recours au numérique dans la reconstitution de sites disparus. Nathalie et Anne Thirion utilisent l'exemple du site de l'ancien marché Sainte-Anne et du Parlement du Canada à Montréal; pour restituer le cadre bâti en 3D, elles ont eu recours aux sources archivistiques et archéologiques numérisées qui permettent de tester des hypothèses sur le cadre bâti et sa modélisation paramétrique en 3D. Robert Vergnieux, dans la même partie, fait part de plus de trente ans de pratique en patrimoine du laboratoire bordelais Archéovision mariant archéologie et informatique pour modéliser des sites disparus. Toutes ces modélisations 3D ont figuré dans des expositions de musées et ont fait l'objet d'une médiation exemplaire. Leurs travaux montrent qu'il est possible de concilier objectifs patrimoniaux, innovations technologiques et mises en valeur. Léon Robichaud, quant à lui, présente le système de cartographie géohistorique (SCHEMA) : à partir de banques de données constituées, on transpose sur des cartes les phénomènes étudiés ; mieux, l'auteur illustre ces travaux à travers quelques exemples probants de la valeur de ce système. Dans les travaux de Harold Bérubé, "Vendre la banlieue aux Montréalais », le Schema illustre la répartition spatiale des publicités de banlieues ou encore, dans le cas de la recherche de Michelle Comeau, «Les commerces d'alimentation du Faubourg à m'lasse ».

Trois contributions de la deuxième partie portent sur l'histoire locale et le patrimoine de proximité. Paul-André Linteau s'intéresse à la rue montréalaise comme microcosme révélateur de la société urbaine en tant que patrimoine. Rues, grandes artères et segments de rues montréalaises ont été l'objet de nombreux travaux qui constituent une très riche historiographie analysée par l'auteur ; de cet ensemble, il fait ressortir les points majeurs. La rue est un témoin du développement urbain, et un espace de circulation et de communication lié aux développements techniques des transports. Mais c'est également, en termes de patrimoine immatériel, un milieu de vie et une forme de sociabilité. Ce type de sociabilité est perceptible également à l'échelle du quartier. 
Harold Bérubé appréhende l'histoire de Montréal par les quartiers. La sociabilité dans ce cas se fait à l'échelle du voisinage dans le quartier. C'est la mémoire qui est au fondement de la personnalité d'un quartier de même qu'au sentiment d'attachement à certains aspects du cadre bâti ou d'espaces particuliers. En ce sens, c'est le quartier imaginé qui patrimonialise. C'est un patrimoine de proximité en quelque sorte.

Fernand Harvey aborde le patrimoine de proximité dans les régions du Québec. Le patrimoine de proximité est celui qui est au plus près de soi dans les collectivités locales et qui lui confère sa charge symbolique. C'est le patrimoine d'en bas. D'autre part, il y a le patrimoine d'en haut celui de l'État (municipal, provincial et national). L'auteur analyse comment le patrimoine d'en bas et le patrimoine d'en haut interagissent et font évoluer la notion de patrimoine de 1920 à nos jours. Le lecteur a besoin de ce regard en surplomb pour toutes les régions du Québec.

Dans la troisième partie, nous encourageons le lecteur à se plonger dans l'article de Joanne Burgess et Michelle Comeau qui rendent compte de leurs recherches de longue haleine sur le commerce à Montréal en trois chantiers : les magasins-entrepôts, les grands magasins, l'infrastructure commerciale d'un quartier populaire, le quartier Sainte-Marie et les visages du commerce de l'alimentation. Ces recherches sur ces quartiers mettent en valeur un très riche patrimoine archivistique et iconographique témoin d'un milieu de vie et de travail et d'un esprit des lieux. En outre, autre pièce importante de l'empire du commerce à Montréal : le patrimoine portuaire et le système ville-port, sujet du texte d'Alain Gelly. Il s'agit d'un patrimoine naturel, industriel, urbain et immatériel. Les recherches du LHPM sur le patrimoine portuaire débutent en 2007. En 2011, le laboratoire développe un vaste programme de recherche avec « Montréal plaque tournante du commerce et de l'industrie », encore en cours.

Sans l'ombre d'un doute les recherches du LHPM contribuent à l'histoire de Montréal et reflètent l'évolution de la notion de patrimoine. Comme le remarque Fernand Harvey, le patrimoine d'en haut (État) a défini et redéfini la notion depuis les années 1920 jusqu'à la loi sur le patrimoine culturel de 2011 et cela partout au Québec. L'autre élément que cet auteur a observé est que l'expertise en patrimoine n'est plus seulement le fait des experts de l'État. Il existe une expertise patrimoniale et muséale à caractère scientifique partout au Québec, ce dont il faut nous réjouir. À notre avis, ce livre va contribuer à nourrir la réflexion chez les porteurs de cette expertise et les praticiens de l'histoire publique.

Cylvie Claveau Université du Québec à Chicoutimi 